\title{
The Outpatient Training Gap: A Pilot Study
}

\author{
Raphaela Lipinsky DeGette, MD, MS; Margae Knox, MPH; Thomas Bodenheimer, MD, MPH
}

\begin{abstract}
BACKGROUND AND OBJECTIVES: Most family medicine residency training takes place in hospitals, which is not reflective of the outpatient care practiced by most primary care clinicians. This pilot study is an initial exploration of family medicine residency directors' opinions regarding this outpatient training gap.
\end{abstract}

METHODS: The authors surveyed 11 California family medicine residency program directors in 2017-2018 about factors that influence decisions regarding allocation of residents' inpatient and outpatient time. Nine of the 11 program directors agreed to be interviewed. We analyzed the interviews for common themes.

RESULTS: The participating program directors were generally satisfied with inpatient and outpatient balance in their residents' schedules. Factors identified as promoting inpatient training included the need for resident staffing of hospital services, the educational value of inpatient rotations, and a lack of capacity in continuity clinics. From the program directors' perspective, residency funding played no direct role in curriculum planning. Program directors also felt that the ACGME requirements prescribing 1,650 continuity clinic visits throughout residency inhibited the development of creative outpatient training opportunities.

CONCLUSIONS: Family medicine residency program directors participating in this exploratory study did not feel that their programs overly emphasized inpatient care and training.

(Fam Med. 2020;52(2):131-4.)

doi: 10.22454/FamMed.2020.369455

A mericans receive the majority of their health care in an outpatient setting, yet most graduate medical education takes place in hospitals. In particular, the discrepancy between primary care residency training and career practice leaves many graduates inadequately prepared to begin an outpatient career. ${ }^{1,2} 2011$ data from the American Medical Association shows that, on average, family medicine residents only spend about one-third of their training in ambulatory settings. ${ }^{3}$ Addressing this outpatient training gap could help to harmonize family medicine residency training with the scope of practice of family physicians throughout their careers.

Much has been written about factors that might bias graduate medical education (GME) training toward inpatient medicine. Historically, most clinical training occurred in hospitals, where "house officers" cared for ill patients. ${ }^{4}$ This inpatient focus became the culture of medical education despite an increasingly outpatient-based medical landscape. ${ }^{2}$ In addition, the GME funding structure incentivizes hospital training. Medicare heavily finances residency programs with over $\$ 10$ billion per year. These funds are allocated to hospitals sponsoring residency programs, rather than to residency programs themselves. ${ }^{5}$ Tying funding to hospitals discourages ambulatory training, where most people now receive care. ${ }^{6}$ Family medicine is most impacted by the hospital-first orientation of most residency training, since only $28 \%$ of recently graduated family physicians practice in-patient medicine. ${ }^{7}$

We hypothesized that family medicine residency directors would agree that (1) there is an outpatient training gap and that residents' ambulatory time should increase; and (2) the outpatient training gap is the result of how GME is funded, with most funding directed to hospitals rather than to residency programs, giving hospitals control over the allocation of residents' time. As an exploratory pilot study, we surveyed and interviewed California family medicine residency directors to obtain their views on the outpatient training gap.

From the University of California, San Francisco (Dr DeGette) Center for Excellence in Primary Care (Dr Bodenheimer and Ms Knox). 


\section{Methods}

We invited program directors from all 55 nonmilitary family medicine residency programs in California to participate in the pilot. We sent personalized email invitations from October 2017 through March 2018, with up to two reminder emails to nonrespondents. Participation was voluntary and uncompensated. The University of California San Francisco Institutional Review Board designated the study exempt.

If the program director agreed to participate, we sent an information sheet and confidential survey link. The survey contained nine questions about the demographics of the residency program, as well as a request to rank several factors in order of influence on inpatient/outpatient scheduling (Table 1). This questionnaire informed follow-up interviews.

We asked all respondents who answered the survey to participate in a telephone interview. We used an interview guide developed from two pilot interviews (Table 2). All interviews were recorded and transcribed. Two authors independently coded transcripts to identify common codes and develop themes. Coding was done using Atlas.ti software, version 8.0 (https://atlasti.com). The mean and ranges of survey responses were calculated using Microsoft Excel.

\section{Results}

\section{Survey Responses}

Of the 55 California program directors contacted, 11 completed the survey ( $20 \%$ response rate), and nine of those (16\% response rate) completed an interview. In response to "What factor is most important when setting your residents' schedules?" respondents ranked accreditation requirements highest, followed by learning opportunities, hospital staffing needs, tradition, and lastly, funding considerations (Table 3). The program directors interviewed were generally satisfied with the inpatient and outpatient balance in their residents' schedules. Selected comments from the residency director interviews are provided in Table 4.

\section{Discussion}

In 2014, the Institute of Medicine published a seminal report on graduate medical education, stating that "By distributing funds directly to teaching hospitals, the Medicare payment system discourages physician training outside the hospital, in clinical settings where most health care is delivered." 1 Yet we found that family medicine program directors participating in our study did not feel that inpatient care was overemphasized, and did not consider the impact of graduate medical education financing in prioritizing inpatient rotations over clinic time. The program directors tended not to view their programs as inpatient-heavy, valued the knowledge gained during hospital rotations, and felt that the residents had sufficient ambulatory training.

Program directors do not view inpatient rotations as competing with clinic time, perhaps because family medicine residents need competency in a broad scope of practice.

Recently, interest has grown in the Clinic First concept that places greater priority on ambulatory care and teaching. ${ }^{8}$ Clinic First does not imply that in-patient care should be second, but rather proposes actions that improve clinic functioning, such as designing resident schedules to enhance continuity of care, having fewer faculty physicians spending more time in the clinic, building stable primary care teams, engaging residents as coleaders in practice improvement, and increasing resident time in clinic. Perhaps the last principle-increasing resident clinic time-needs to be reevaluated given the opinions of the residency directors reported here.

\section{Table 1: Survey Questions}

\begin{tabular}{l}
\hline 1. What is your program's setting? \\
\hline 2. What year did your residency program start? \\
\hline 3. What is the number of patient visits per year in your primary clinic? \\
\hline 4. How many faculty FTE do you have? \\
\hline 5. Are there other residency programs at your institution? \\
6. What factors determine how much time your residents spend in inpatient settings? Please rank the following factors \\
from most to least important. \\
- Tradition \\
- Hospital staffing needs \\
- Lunding considerations (like maximizing hospital reimbursements) \\
\hline 7. Are there any other factors that are important in determining how much time residents spend inpatient? \\
\hline 8. What is the number of continuity clinic patient visits a resident will complete during his/her time in the program? \\
\hline 9. What is your best estimate of continuity clinic half-days per year? \\
\hline 10. What is the longest time a resident would be out of continuity clinic entirely?
\end{tabular}


Table 2: Interview Guide

I. Current funding streams

- Do you know how your residency program is currently funded?

- Examples of funding sources include Medicare, Medicaid, Teaching Health Center (THC) funding, state or local grants, private foundations or donors

- How much do you know about different funding sources available for residency programs?

- How would you receive your funding in an ideal world?

II. Inpatient-to-outpatient balance

- What is the ratio of inpatient-to-outpatient blocks in your residents' first year? Second? Third?

- What is the longest time a resident would be out of clinic?

- How many half-days are spent in clinic per block?

- Could you send me a template for resident schedules?

III. Factors influencing curricular decisions

- What are the most important factors in determining how much outpatient training residents have?

- How much of an impact does the RRC/residency requirements have on your schedule?

- Did/do you consider funding sources when constructing a curriculum for your residents?

- Do you think the hospital you partner with takes funding sources into account when collaborating on resident curriculum? For example, some funding sources are tied to inpatient time. Do you think hospital administrators take this into account when planning how GME fits into the hospital?

- Would you make the resident schedule the same way if you had independent control over finances (rather than relying on the hospital)?

- If you wanted to increase the number of sessions residents spend in clinic, what would stand in your way?

IV. Effect of Medicare cap

- Have you added resident spots since 1997? Why or why not?

Table 3: Factors Influencing Resident Scheduling (Ranked From 1-6)

\begin{tabular}{|l|l|}
\hline \multicolumn{1}{|c|}{$\begin{array}{c}\text { Ranking of Factors Influencing Inpatient } \\
\text { and Outpatient Training }\end{array}$} & Average Ranking (Lower Number=Higher Priority) \\
\hline Residency accreditation requirements & 2.2 \\
\hline Learning opportunities & 2.5 \\
\hline Hospital staffing needs & 3.0 \\
\hline Tradition & 3.1 \\
\hline Funding considerations & 4.8 \\
\hline Other & 5.5 \\
\hline
\end{tabular}

The major limitation of this pilot study is the small number of residency directors who participated, their confinement to California, and the fact that they did not constitute a representative sample of family medicine residency directors. Moreover, a multistakeholder perspective- including clinic medical directors, residents, and faculty-may have revealed different opinions regarding the outpatient training gap. In particular, clinic medical directors, whose responsibility is focused on the clinic rather than the residency as a whole, may be more concerned with the gap. It is not possible to generalize from the small number of program directors' responses because there is likely bias in the responses based on who chose to participate in the pilot study. Further research to explore opinions on the in-patient/ambulatory balance would require a larger national sample of family medicine residency directors or of multiple stakeholders.

\section{Conclusion}

We hypothesized that family medicine residency directors would agree (1) that there is an outpatient training gap and that residents' ambulatory time should increase, and (2) that the outpatient training gap is the result of how graduate medical education is funded. However, the family medicine residency program directors participating in this study did not feel that their programs overly emphasized inpatient care and teaching, nor did they feel that graduate medical education financing has a role in prioritizing inpatient rotations over ambulatory care. 
Table 4: Selected Comments From Residency Directors

\begin{tabular}{|c|c|}
\hline Themes & Residency Director Comments \\
\hline Satisfaction with curricular balance & $\begin{array}{l}\text { "I think we're doing a pretty good job of making sure } \\
\text { everybody has enough clinic time to get competent at } \\
\text { outpatient medicine." } \\
\text { "Overall, we do pretty well with getting [residents] in the } \\
\text { clinic." }\end{array}$ \\
\hline Impact of GME funding & $\begin{array}{l}\text { "The GME [funding] part... doesn't really factor into } \\
\text { [resident scheduling]." } \\
\text { "There's really no pressure at all from leadership to spend } \\
\text { more time in the hospital." }\end{array}$ \\
\hline Educational value if inpatient training & $\begin{array}{l}\text { "I think they do the most intense learning on the inpatient } \\
\text { side." } \\
\text { "I don't think I would curtail, really, our inpatient coverage, } \\
\text { because I think that provides really excellent training." }\end{array}$ \\
\hline Need to maintain hospital staffing & $\begin{array}{l}\text { "The residents traditionally have taken care of everyone } \\
\text { admitted to the hospital ... the problem is who's going to } \\
\text { provide the coverage." } \\
\text { "That dictates how we schedule, because we have } 365,24 / 7 \\
\text { coverage on those three [inpatient]services." }\end{array}$ \\
\hline Clinics already at capacity & $\begin{array}{l}\text { "The main thing preventing me from putting our residents } \\
\text { in clinics more is that we don't have room in our clinics for } \\
\text { them. It's that simple." }\end{array}$ \\
\hline Residents as barriers to change & $\begin{array}{l}\text { "I say I'm going to pull you out for an extra clinic..., they } \\
\text { will say it's really disruptive. How are we going to take care } \\
\text { of our patients in the hospital?" } \\
\text { "Whenever we talk about [less inpatient time] we actually } \\
\text { get quite a significant resistance from residents." }\end{array}$ \\
\hline $\begin{array}{l}\text { The ACGME requirement that family medicine residents } \\
\text { provide } 1,650 \text { continuity clinic visits during their residency }\end{array}$ & $\begin{array}{l}\text { "By [setting the 1,650 requirement], they have hamster } \\
\text { wheeled residency programs for seeing highly acute patients } \\
\text { with lots of disease, and having to crank people through. } \\
\text { That's not a great way to teach people to enjoy the practice } \\
\text { of primary care, in my view." }\end{array}$ \\
\hline
\end{tabular}

ACKNOWLEDGMENTS: The authors thank the staff of the UCSF Center for Excellence in Primary Care (CEPC), including Rachel Willard-Grace and Beatrice Huang. This study was presented at the UCSF Family and Community Medicine Rodnick Colloquium on May 31,2018

FUNDING STATEMENT: This study was supported by funding from the UCSF Primary Care Leadership Academy Fellowship.

CORRESPONDING AUTHOR: Address correspondence to Dr Thomas Bodenheimer,UCSF Center for Excellence in Primary Care, 995 Potrero Ave, Ward 83, San Francisco, CA 94110.415-269-5021. Thomas.Bodenheimer@ ucsf.edu.

\section{References}

1. Institute of Medicine. Graduate Medical Education That Meets the Nation's Health Needs. Washington, DC: The National Academies Press; 2014. http://www.nationalacademies. org/hmd/Reports/2014/Graduate-Medical-Education-That-Meets-the-Nations-Health-Needs. aspx. Accessed November 20, 2019.

2. UCSF Center for Excellence in Primary Care High-Functioning Primary Care Residency Clinics: Building Blocks for Providing Excellent Care and Training. Washington DC Association of American Medical Colleges; 2016. https://store.aamc.org/high-functioning primary-care-residency-clinics.html. Accessed November 20, 2019.

3. Wynn BO, Smalley R, Cordasco KM. Does It Cost More to Train Residents or to Replace Them? A Look at the Costs and Benefits of Operating Graduate Medical Education Programs. Santa Monica, CA: RAND Corporation; 2013.
4. Howell JD. A History of medical residency. Rev Am Hist. 2016;44(1):126-131.

5. United States Government Accountability Office. Physician Workforce: HHS Needs Better Information to Comprehensively Evaluate Graduate Medical Education Funding; 2018.

6. Chen C, Xierali I, Piwnica-Worms K, Phillips R. The redistribution of graduate medical education positions in 2005 failed to boost primary care or rural training. Health Aff (Millwood). 2013;32(1):102-110.

7. Weidner AKH, Phillips RL Jr, Fang B, Peterson LE. Burnout and scope of practice in new family physicians. Ann Fam Med. 2018;16(3):200205.

8. Gupta R, Barnes K, Bodenheimer T. Clinic First: 6 actions to transform ambulatory residency training. J Grad Med Educ. 2016;8(4):500-503. 